\title{
Improving Asynchronous Motor Speed and Flux Loop Control by Using Hybrid Fuzzy-SMC Controllers
}

\author{
Ismail Bendaas $\quad$ Farid Naceri Sebti Belkacem \\ Department of Electrical Engineering, Batna University, Batna 05000, Algeria
}

\begin{abstract}
This paper presents a new method combining sliding mode control (SMC) and fuzzy logic control (FLC) to enhance the robustness and performance for a class of non-linear control systems. This fuzzy sliding mode control (FSMC) is developed for application in the area for controlling the speed and flux loops of asynchronous motors. The proposed control law can solve those problems associated with the conventional control by sliding mode control, such as high current, flux and torque chattering, variable switching frequency and variation of parameters, in which a robust fuzzy logic controller replaces the discontinuous part of the classical sliding mode control law. Simulation results of the proposed FSMC technique on the speed and flux rotor controllers present good dynamic and steady-state performances compared to the classical SMC in terms of reduction of the torque chattering, quick dynamic torque response and robustness to disturbance and variation of parameters.
\end{abstract}

Keywords: Induction motor, sliding mode control, fuzzy logic control, fuzzy sliding mode control, chattering phenomenon.

\section{Introduction}

Induction motors (IM) are most suitable for industrial drives because of their simple and robust structure, high torque-to-weight ratio, high reliability and ability to operate in hazardous environment. However, their control is a challenging task, because the rotor current, responsible for the torque production, is induced from the stator current and also contributes to net air-gap flux, resulting in the coupling between torque and flux ${ }^{[1]}$. The input-output linearization has been frequently used in nonlinear systems to find a direct relation between the system output and input in order to implement a control law. However, the complexity and the presence of high nonlinearities in some cases do not allow an exact compensation for these nonlinearities to obtain the desired tracking performance in the presence of external disturbances.

Known by its robustness and simplicity of implementation, the sliding mode has been largely used to control a large class of nonlinear systems ${ }^{[2-6]}$. In order to be attractive, the surface called sliding is defined depending on the system states. The synthesized global control consists of two terms: the first allows the approach to this surface and the second maintains sliding along it towards the origin of the phase plane. The global control ensures a good tracking performance, rapid dynamic and short response time ${ }^{[7,8]}$.

However, this control law represents a disadvantage in using the sign function in the control law to ensure the passage of the approach phase to the sliding mode. This gives rise to the phenomenon of chattering that consists of sudden and rapid variations of the control signal, which can excite the high frequency of the process and cause damages.

A fuzzy logic control has been a subject of active research since the work of Mamdani in $1974^{[9]}$. For more explain the concept of fuzzy logic control (FLC) is used the qualitative knowledge of a practice to design a controller. It is generally applicable to systems that are in the wrong modeled, but

Regular paper

Manuscript received June 22, 2013; revised August 5, 2013 the qualitative knowledge of experienced operators is available for design. It is particularly suitable for systems with uncertain or complex dynamics. Generally, a fuzzy control algorithm consists of a set of decision rules and heuristically can be considered as a nonmathematical control algorithm, in contrast to a conventional feedback control algorithm ${ }^{[10]}$. To remedy the disadvantage of the chattering phenomenon, more works ${ }^{[3,11-13]}$ have been focused on the combination of sliding mode control with fuzzy logic control.

In this paper, we present a new hybrid nonlinear control method which is based on sliding mode control and fuzzy logic method. The sliding mode control approach is employed to design the induction motor speed and flux rotor controllers. The dynamic decouple control is accomplished under the condition that the parameter of stator resistance variants and the load torque are time variants. In order to reduce the undesired chattering phenomenon of signum function, the fuzzy control method is used, which is used to design a new fuzzy switching function to replace the traditional sliding mode signum function. Finally, simulations and a comparison are presented to demonstrate the contribution of this approach.

\section{Model of an induction motor}

The model of a three-phase induction motor in the laboratory frame $(\alpha, \beta)$ is given by the following equations.

The voltage equations become

$$
\left\{\begin{array}{l}
V_{s \alpha}=R_{s} i_{s \alpha}+\frac{\mathrm{d} \phi_{s \alpha}}{\mathrm{d} t} \\
V_{s \beta}=R_{s} i_{s \beta}+\frac{\mathrm{d} \phi_{s \beta}}{\mathrm{d} t} \\
V_{r \alpha}=0=R_{r} i_{r \alpha}+\frac{\mathrm{d} \phi_{r \alpha}}{\mathrm{d} t}+\omega \phi_{r \beta} \\
V_{r \beta}=0=R_{r} i_{r \beta}+\frac{\mathrm{d} \phi_{r \beta}}{\mathrm{d} t}-\omega \phi_{r \alpha} .
\end{array}\right.
$$

The expressions of electromagnetic torque and the movement for the induction motor are as 


$$
\begin{gathered}
T_{e}=p \frac{M}{L_{r}}\left(\phi_{r \alpha} i_{s \beta}-\phi_{r \beta} i_{s \alpha}\right) \\
J \frac{\mathrm{d} \Omega}{\mathrm{d} t}=T_{e}-T_{L}-f \Omega .
\end{gathered}
$$

The state model of the induction motor is a nonlinear multivariable system taking the following form

$$
\dot{x}(t)=f(x)+g(x) u(t) .
$$

The model of the induction motor, driven by (1), (2) and (3), is defined by the nonlinear system as

$$
\begin{aligned}
\frac{\mathrm{d}}{\mathrm{d} t}\left[\begin{array}{c}
i_{s \alpha} \\
i_{s \beta} \\
\phi_{r \alpha} \\
\phi_{r \beta} \\
\omega
\end{array}\right]= & {\left[\begin{array}{c}
-\gamma i_{s \alpha}+\frac{K}{T_{r}} \phi_{r \alpha}+p K \omega \phi_{r \beta} \\
-\gamma i_{s \beta}-p K \omega \phi_{r \alpha}+\frac{K}{T_{r}} \phi_{r \beta} \\
\frac{M}{T_{r}} i_{s \alpha}-\frac{1}{T_{r}} \phi_{r \alpha}-p \omega \phi_{r \beta} \\
\frac{M}{T_{r}} i_{s \beta}+p \omega \phi_{r \alpha}-\frac{1}{T_{r}} \phi_{r \beta} \\
\mu\left(\phi_{r \alpha} i_{s \beta}-\phi_{r \beta} i_{s \alpha}\right)-\frac{f}{J} \omega-\frac{T_{L}}{J}
\end{array}\right]+} \\
& {\left[\begin{array}{cc}
\alpha & 0 \\
0 & \alpha \\
0 & 0 \\
0 & 0 \\
0 & 0
\end{array}\right]\left[\begin{array}{c}
V_{s \alpha} \\
V_{s \beta}
\end{array}\right] }
\end{aligned}
$$

where

$$
\begin{aligned}
& K=\frac{M}{\sigma L_{s} L_{R}}, \gamma=\frac{1}{\sigma L_{s}}\left(R_{s}+R_{r} \frac{M^{2}}{L_{r}^{2}}\right), T_{r}=\frac{L_{r}}{R_{r}} \\
& \mu=\frac{p M}{J L_{r}}, \alpha=\frac{1}{\sigma L_{s}}, \sigma=1-\frac{M^{2}}{L_{s} L_{R}}
\end{aligned}
$$

$i_{s \alpha, \beta}:$ Component of the stator current reference.

$\phi_{r \alpha, \beta}$ : Component of the rotor flux reference.

$\omega$ : Angular speed of rotation.

$V_{s \alpha, \beta}$ : Component of stator voltage reference.

$R_{s}, R_{r}$ : Resistances of stator and rotor windings.

$L_{s}$ : Stator inductance matrix.

$L_{r}$ : Rotor inductance matrix.

$M$ : Matrix of stator-rotor mutual inductances.

$p$ : Number of pole pairs.

$J$ : The moment of inertia.

$f:$ The friction coefficient.

$\sigma$ : The dispersion coefficient of Blondel.

$T_{e}:$ The electromagnetic torque.

$T_{L}:$ The load torque.

$\Omega$ : Mechanical rotation speed of the rotor.

\section{Basic concepts of sliding mode con- trol}

A sliding mode controller (SMC) is a variable structure controller (VSC) ${ }^{[14]}$. A variable structure system is characterized by the choice of a function and a switching logic. This choice will switch at any time between the different structure to combine the useful properties of each of these structures in order to have the desired behavior of the system. Consider the system described by $(4)^{[3,15,16]}$.

The SMC design consists of the following steps:
1) Design a switching manifold $s$ in the state space to represent a desired system dynamics, which is of lower order than the dimension of the given plant; $s$ is defined by

$$
s=\left\{x \in \mathbf{R}^{n}: s(x)=0\right\}
$$

where $s(x) \in \mathbf{R}^{n}$ is called the switching function.

2) Design a variable structure control

$$
u=\left\{\begin{array}{lll}
u_{\max }^{+}(x) & \text { Si } & s(x)>0 \\
u_{\min }^{-}(x) & \text { Si } & s(x)<0
\end{array}\right.
$$

such that any state $x$ outside the switching surface is driven to reach this surface in finite time, i.e., the condition $s(x)=0$ is satisfied in a finite time. Once the sliding mode takes place on the switching surface, the desired system dynamics is followed up. This procedure makes the VSC system globally asymptotically stable ${ }^{[6]}$.

Equation (6) is a variety of sliding that divides the state space into two disjoints $s(x)>0$ and $s(x)<0$.

The switching logic is designed to force the trajectory to follow the surface switching. We then say that the trajectory of the system sliding along the surface switching $s(x)=$ 0 is referred to as the phenomenon of chattering ${ }^{[4,6,13]}$.

So we are interested in calculating the equivalent control and then to calculate the attractive control defined in the state space (4). The control vector $u$ is composed of two parameters $u_{e q}$ and $\Delta u$, we must find the analytical expression of the control $u(t)$.

We have

$$
\begin{aligned}
& \dot{s}(x)=\frac{\mathrm{d} s}{\mathrm{~d} t}=\frac{\partial s}{\partial x} \frac{\partial x}{\partial t}= \\
& \frac{\partial s}{\partial x}\left\{f(x, t)+g(x, t) u_{e q}(t)\right\}+\frac{\partial s}{\partial t}\{g(x, t) \Delta u\} .
\end{aligned}
$$

During the sliding mode and the standing system, the surface is zero, therefore its derivative and discontinuous part are zero. Hence, we deduce the expression of the equivalent control as

$$
u_{e q}(t)=-\left\{\frac{\partial s}{\partial t} g(x, t)\right\}^{-1}\left\{\frac{\partial s}{\partial x} f(x, t)\right\} .
$$

As the equivalent control can take a finite value, it holds that $\frac{\partial s}{\partial x} g(x, t) \neq 0$.

During the convergence mode and the replacing of the equivalent control by its expression in (8), we find the new expression of the derivative of the surface as

$$
\dot{s}(x)=\frac{\partial s}{\partial x}\{g(x, t) \Delta u\} .
$$

The problem is to find $\Delta u$ such that

$$
s(x) \dot{s}(x)=s(x) \frac{\partial s}{\partial x}\{g(x, t) \Delta u\}<0 .
$$

The simplest form that can take the discrete control is a relay. In this case, the attractive control is as

$$
\Delta u=-k \operatorname{sgn}(s(x, t)) .
$$

Substituting (12) into (11), we obtain

$$
s(x) \dot{s}(x)=\frac{\partial s}{\partial t} g(x, t) k|s(x)|<0 .
$$

It is necessary that $\frac{\partial s}{\partial t} g(x, t) k|s(x)|<0$ satisfies the conditions of attractiveness of the sliding surface. The positive 
gain $k$ is chosen to satisfy the condition (13). The choice of this gain is very influential, because if it is very small, the response time will be very long, and if it is chosen very large, we will have large oscillations at the control system. These oscillations can excite the dynamics neglected (the chattering phenomenon $)^{[2,3,7]}$.

\section{Fuzzy sliding mode controller design}

The conventional sliding mode control is based on the discontinuous function of state variables in the system that is used to create a "sliding surface". When this surface is reached, the discontinuous function keeps the trajectory on the surface so that the desired system dynamics is obtained ${ }^{[6,17,18]}$.

In this paper, the controllers of speed and rotor flux are substituted by a fuzzy sliding mode controller to obtain a robust performance. By keeping one part of the equivalent control (SMC) and adding the fuzzy logic control (FLC), we obtain the new method control (FSMC) as shown in Fig. $1^{[10]}$.

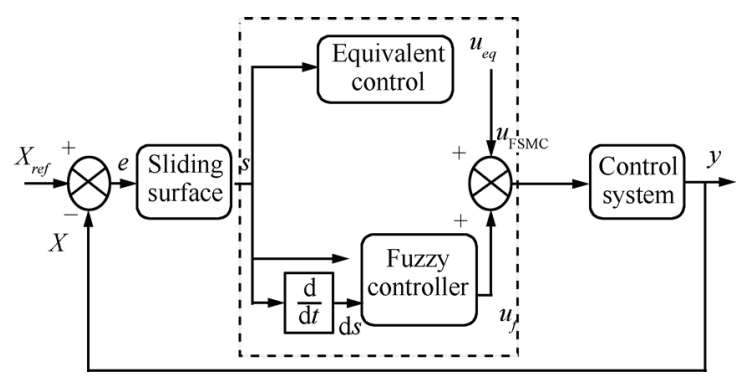

Fig. 1 The diagram of FSMC approach

$$
u_{\mathrm{FSMC}}=u_{e q}+u_{\mathrm{fuzzy}} .
$$

The two parts are combined to provide stability and robustness of the system. The method of control by fuzzy logic approach is adopted to solve the problem of chattering.

\subsection{Synthesis of the SMC controller}

In the design of sliding mode control of speed and rotor flux of the system, the switching function is chosen as ${ }^{[2]}$

$$
\left\{\begin{array}{l}
s_{1}=k_{1} e_{\omega}+\dot{e}_{\omega} \\
s_{2}=k_{2} e_{\phi_{r}}+\dot{e}_{\phi_{r}}
\end{array}\right.
$$

where

$$
\left\{\begin{array}{l}
e_{\omega}=\omega-\omega_{r e f} \\
e_{\phi_{r}}=\phi_{r}-\phi_{r r e f}
\end{array}\right.
$$

In (16), $\omega_{r e f}$ is the speed reference, $\phi_{r r d f}$ is the flux reference; $e_{w}$ is the error between rotor speed and reference speed (input output speed loop), $e_{\phi_{r}}$ is the error between rotor flux and reference flux (input output flux loop).

Beginning with the replacement of (16) into (15), we have

$$
\left\{\begin{array}{l}
s_{1}=k_{1}\left(\omega-\omega_{r e f}\right)+\left(\dot{\omega}-\dot{\omega}_{r e f}\right) \\
s_{2}=k_{2}\left(\phi_{r}-\phi_{r r e f}\right)+\left(2 \phi_{r \alpha} \dot{\phi}_{r \alpha}+2 \phi_{r \beta} \dot{\phi}_{r \beta}-\dot{\phi}_{r r e f}\right)
\end{array}\right.
$$

where $k_{1}$ and $k_{2}$ are positive gains.

After substitution of (17) and (15), we arrive

$$
\left\{\begin{aligned}
s_{1}= & \frac{k_{1}}{\mu}\left(\omega-\omega_{r e f}\right)+\left(i_{s \beta} \phi_{r \alpha}-i_{s \alpha} \phi_{r \beta}\right)-\frac{T_{L}}{J \mu}-\frac{\dot{\omega}_{r e f}}{\mu} \\
s_{2}= & \frac{T_{r}}{2} k_{2}\left(\phi_{r}-\phi_{r r e f}\right)+\left[M\left(i_{s \alpha} \phi_{r \alpha}+i_{s \beta} \phi_{r \beta}\right)-\phi_{r}\right]- \\
& \frac{T_{r}}{2} \dot{\phi}_{\text {rref }}
\end{aligned}\right.
$$

where $k_{1}$ and $k_{2}$ are positive gains. The development of derivatives of the surfaces gives

$$
\left\{\begin{aligned}
\dot{s}_{1}= & \left(k_{1}-\frac{1}{T_{r}}-\gamma\right) \mu f_{2}-k_{1} \frac{T_{L}}{J}-p \mu \omega\left(f_{1}+K \phi_{r}\right)- \\
& k_{1} \dot{\omega}_{r e f}-\ddot{\omega}+\alpha \mu \phi_{r \alpha} V_{s \alpha}-\alpha \mu \phi_{r \beta} V_{s \beta} \\
\dot{s}_{2}= & \frac{2}{T_{r}}\left(\frac{T_{r} k_{2}}{2}-1\right) \dot{\phi}_{r}+ \\
& \frac{2 M}{T_{r}}\left(\frac{M}{T_{r}} f_{3}-\left(\frac{1}{T_{r}}+\gamma\right) f_{1}+\frac{K}{T_{r}} \phi_{r}+p \omega f_{2}\right)- \\
& k_{2} \dot{\phi}_{r r e f}-\ddot{\phi}_{r r e f}+\frac{2 \alpha}{T_{r}} M \phi_{r \beta} V_{s \beta}+\frac{2 \alpha}{T_{r}} M \phi_{r \alpha} V_{s \alpha}
\end{aligned}\right.
$$

where

$$
\left\{\begin{array}{l}
f_{1}=i_{s \alpha} \phi_{r \alpha}+i_{s \beta} \phi_{r \beta} \\
f_{2}=i_{s \beta} \phi_{r \alpha}+i_{s \alpha} \phi_{r \beta} \\
f_{3}=i_{s \alpha}^{2}+i_{s \beta}^{2} .
\end{array}\right.
$$

The necessary condition for the system states follow the trajectory defined by the sliding surfaces is $s_{i}=0$. For the nominal system function, the equivalent control $u_{e q}$ is the control ensuring $\dot{s}=0$, which gives

$$
\left\{\begin{array}{c}
\left(k_{1}-\frac{1}{T_{r}}-\gamma\right) f_{2}-k_{1} \frac{T_{L}}{\mu J}-p \omega\left(f_{1}+K \phi_{r}\right)- \\
\frac{k_{1}}{\mu} \dot{\omega}_{r e f}-\frac{1}{\mu} \ddot{\omega}=\alpha \phi_{r \beta} V_{s \alpha}-\alpha \phi_{r \alpha} V_{s \beta} \\
\left(\frac{T_{r} k_{2}}{2}-1\right) \dot{\phi}_{r}+M\left(\frac{M}{T_{r}} f_{3}-\left(\frac{1}{T_{r}}+\gamma\right) f_{1}+\right. \\
\left.\frac{K}{T_{r}} \phi_{r}+p \omega f_{2}\right)-\frac{T_{r}}{2} k_{2} \dot{\phi}_{r r e f}-\frac{T_{r}}{2} \ddot{\phi}_{r r e f}= \\
\alpha M \phi_{r \beta} V_{s \beta}+\alpha M \phi_{r \alpha} V_{s \alpha} .
\end{array}\right.
$$

Assume

$$
\left\{\begin{aligned}
A= & \left(k_{1}-\frac{1}{T_{r}}-\gamma\right) f_{2}-k_{1} \frac{T_{L}}{\mu J}-p \omega\left(f_{1}+K \phi_{r}\right)- \\
& \frac{k_{1}}{\mu} \dot{\omega}_{r e f}-\frac{1}{\mu} \ddot{\omega} \\
B= & \left(\frac{T_{r} k_{2}}{2}-1\right) \dot{\phi}_{r}+ \\
& M\left(\frac{M}{T_{r}} f_{3}-\left(\frac{1}{T_{r}}+\gamma\right) f_{1}+\frac{K}{T_{r}} \phi_{r}+p \omega f_{2}\right)- \\
& \frac{T_{r}}{2} k_{2} \dot{\phi}_{r r e f}-\frac{T_{r}}{2} \ddot{\phi}_{r r e f}
\end{aligned}\right.
$$

or

$$
\dot{s}=0 \Rightarrow\left[\begin{array}{c}
A \\
B
\end{array}\right]=\left[\begin{array}{cc}
-\alpha \phi_{r \beta} & \alpha \phi_{r \alpha} \\
\alpha M \phi_{r \alpha} & \alpha M \phi_{r \beta}
\end{array}\right]\left[\begin{array}{c}
V_{s \alpha} \\
V_{s \beta}
\end{array}\right]
$$


we have

$$
F=\left[\begin{array}{c}
A \\
B
\end{array}\right] \text {, and } \Rightarrow\left[\begin{array}{c}
V_{s \alpha} \\
V_{s \beta}
\end{array}\right]=-E^{-1} F=u_{e q} .
$$

\subsection{Design of FLC controller}

The chattering phenomenon is well known as one of the disadvantages of the SMC. In this section, a fuzzy control FLC is introduced to replace the function $k_{1,2} \operatorname{sgn}\left(s_{1,2}\right)$. Since the trajectory of state can reach and move on along the surface of change, a good dynamic steady state can be achieved by the combination of SMC and $\mathrm{FLC}^{[5,18]}$.

The fuzzy controller used in this paper has two inputs and one output, as shown in Fig. 2.

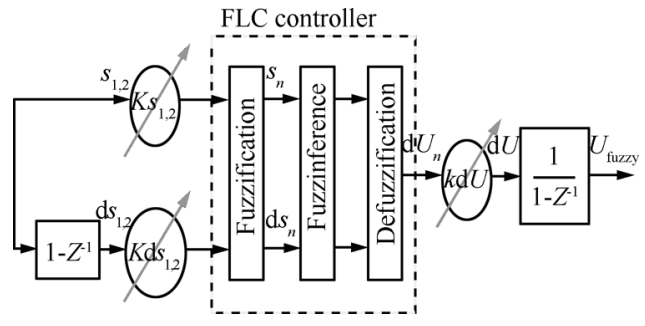

Fig. 2 Fuzzy logic control diagram

The membership functions are defined in Figs. 3 (a) and (b). The fuzzy rule base consists of a collection of linguistic rules of the form ${ }^{[5,19]}$ :

Rule 1: if $s_{1,2}$ is $\mathrm{NB}$, and $\mathrm{d} s_{1,2}$ is $\mathrm{NB}$ then $\mathrm{d} U_{1,2}$ is $\mathrm{NB}$.

Rule 2: if $s_{1,2}$ is $\mathrm{NM}$, and $\mathrm{d} s_{1,2}$ is NB then $\mathrm{d} U_{1,2}$ is NB.

Rule 3: if $s_{1,2}$ is NS, and $\mathrm{d} s_{1,2}$ is NG then $\mathrm{d} U_{1,2}$ is NS.

Rule 49: if $s_{1,2}$ is $\mathrm{PB}$ and $\mathrm{d} s_{1,2}$ is $\mathrm{PB}$ then $\mathrm{d} U_{1,2}$ is $\mathrm{PB}$.

These inferences can be made in a more explicit form of a table, called the decision table (Table 1$)^{[9]}$.

Table 1 Fuzzy inference table

\begin{tabular}{|c|c|c|c|c|c|c|c|c|}
\hline & \multirow{2}{*}{$\mathrm{d} U_{1,2}$} & \multicolumn{7}{|c|}{$\mathrm{d} s_{1,2}$} \\
\hline & & NB & NM & NS & EZ & PS & $\mathrm{PM}$ & PB \\
\hline \multirow{7}{*}{$s_{1,2}$} & NB & NB & NB & NB & NM & NS & NS & EZ \\
\hline & $\mathrm{NM}$ & NB & NM & $\mathrm{NM}$ & NM & NS & $\mathrm{EZ}$ & PS \\
\hline & NS & NB & $\mathrm{NM}$ & NS & NS & EZ & PS & $\mathrm{PM}$ \\
\hline & $\mathrm{EZ}$ & NB & NM & NS & $\mathrm{EZ}$ & PS & $\mathrm{PM}$ & PB \\
\hline & PS & NM & NS & $\mathrm{EZ}$ & PS & PS & PM & PB \\
\hline & $\mathrm{PM}$ & NS & $\mathrm{EZ}$ & PS & $\mathrm{PM}$ & $\mathrm{PM}$ & $\mathrm{PM}$ & PB \\
\hline & $\mathrm{PB}$ & $\mathrm{EZ}$ & PS & PS & $\mathrm{PM}$ & $\mathrm{PB}$ & $\mathrm{PB}$ & PB \\
\hline
\end{tabular}

\section{Sensitivity study and simulation re- sults}

To demonstrate the performance of the technique using the principle the hybrid control by fuzzy sliding mode, we will present simulations of an induction motor controlled by a voltage inverter. This performance is established from the simulation of operating modes: Robustness of the con- trol relative to parametric variations (stator and rotor resistances) followed by a variation of a load torque.
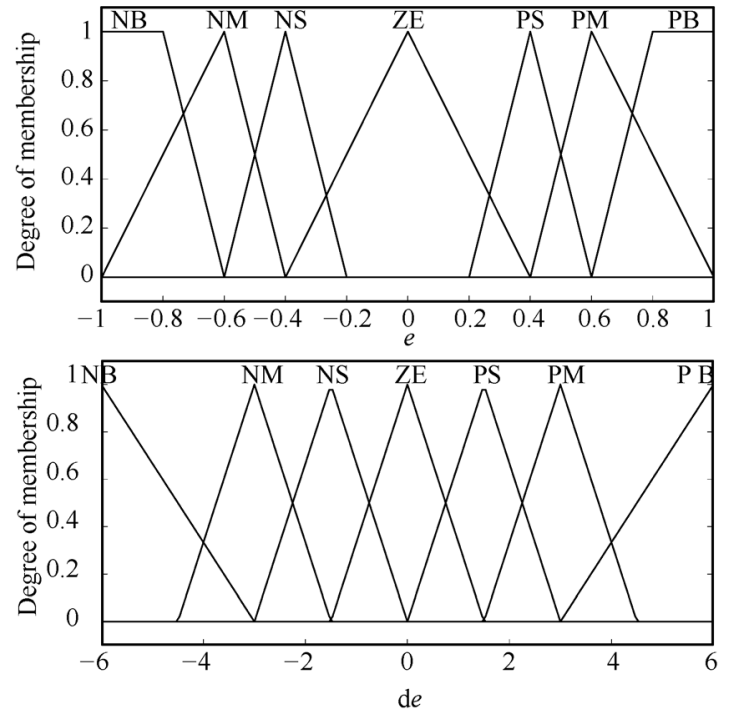

(a) Inputs membership function

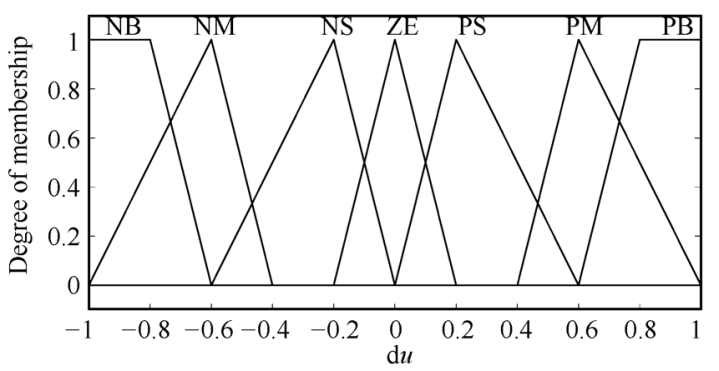

(b) Output membership function

Fig. 3 Membership function

\subsection{Speed variation test with application of a load torque}

To show the hybrid fuzzy sliding mode performances, we simulated the system described in Fig. 4.

The first test concerns the speed evolution and the disturbance rejection of FSMC and SMC controllers. This test is related to the performances of the drive system at low reference speed. When the induction motor is operated at $100 \mathrm{rad} / \mathrm{s}$ under no load, a load torque $5 \mathrm{~N} \cdot \mathrm{m}$ is suddenly applied at $t=0.3 \mathrm{~s}$, followed by a consign inversion $-100 \mathrm{rad} / \mathrm{s}$ at $t=0.4 \mathrm{~s}$ and acceleration again to $15 \mathrm{rad} / \mathrm{s}$. When the induction motor operates in low speed, we eliminate the torque load in $t=0.8 \mathrm{~s}$. A comparison between the proposed control by the FSMC and a conventional control SMC is presented in Figs. 5 (a) and (b). This comparison shows clearly that the FSMC gives good performance. The FSMC controller rejects the load disturbance very rapidly with no overshoot, with a negligible steady state error, maintains the decoupling between a torque and flux and reduces the chattering phenomenon in the electromagnetic response. The conventional control SMC rejects the load disturbance very rapidly with no overshoot and with a negligible steady state error only in the nominal speed and has the chattering phenomenon in electromagnetic torque. 


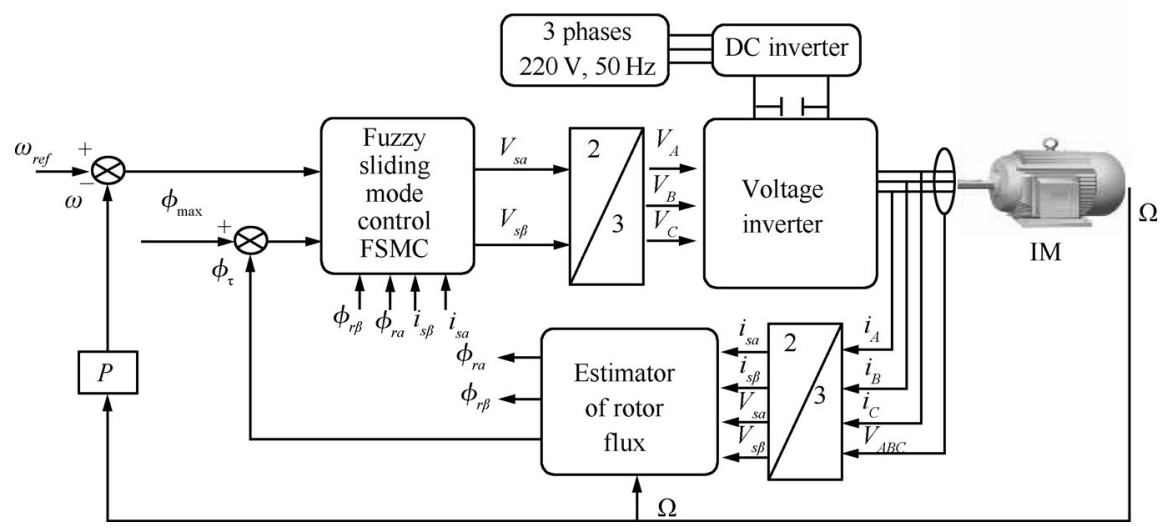

Fig. 4 Block diagram of the proposed FSMC
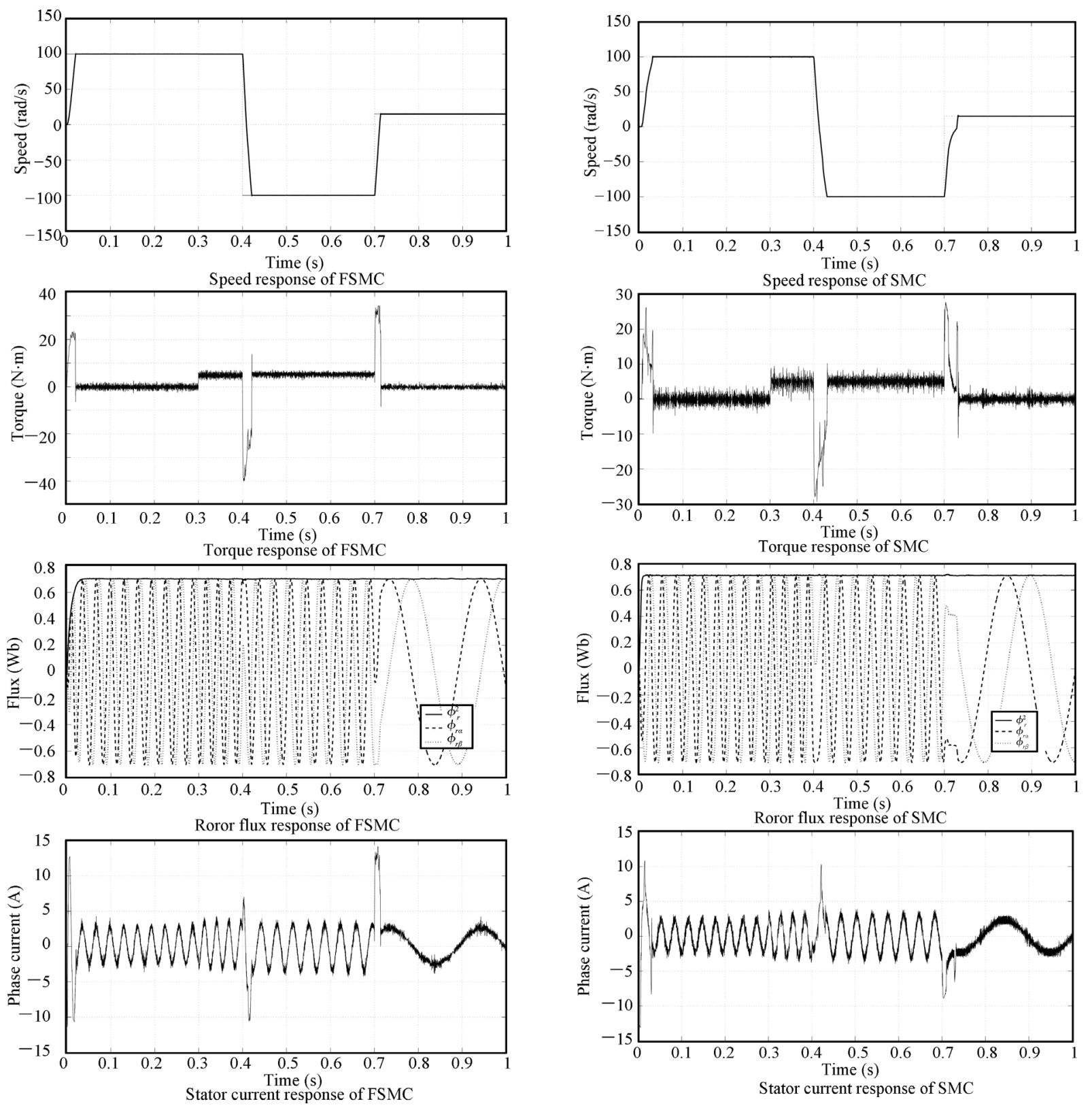

(a) FSMC results

(b) SMC results

Fig. 5 Simulation results under deferent speed references application of a load torque 


\subsection{Robustness test}

In order to test the robustness of the proposed approach, we studied the effect of the parameters uncertainties on the performances and we compared it with the SMC control.

To show the effect of the parameters uncertainties, we simulated the system with different values of the parameter considered and compared the results with the nominal value.

Two cases are considered:

1) The stator and rotor resistances $(50 \%$ and $100 \%$, respectively) as shown in Fig. 6 .

2) The moment of inertia ( $50 \%$ to $100 \%$ ).

To illustrate the performances of control, we simulated the starting mode of the motor without load, and the application of the load $T_{L}=5 \mathrm{~N} \cdot \mathrm{m}$ at $t_{1}=0.3 \mathrm{~s}$ and it is elimination at $t_{2}=0.7 \mathrm{~s}$, in the presence of the variation of parameters considered (the moment of inertia, the stator and rotor resistances) with speed step of $100 \mathrm{rad} / \mathrm{s}$.
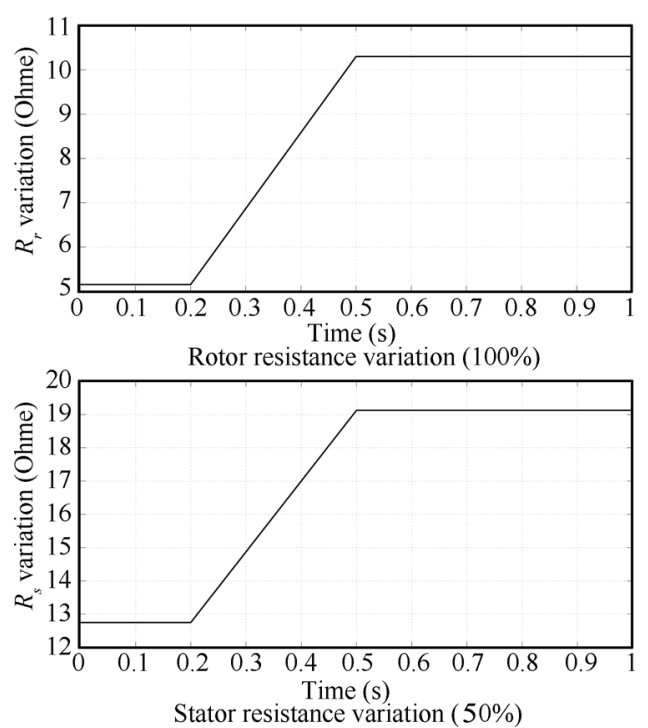

Fig. 6 Stator and rotor resistances

Fig. 7 shows the system response realized by the SMC and FSMC for different values of stator and rotor resistances. Variations of the stator and rotor resistances do not have any effects on the performances of the approach used. In the SMC control, the chattering phenomenon increases during the load period.

\section{Conclusions}

This paper describes a new hybrid approach to reduce the chattering phenomenon based on the combination of the SMC and FLC principles. The control strategy requires less information about the system model and is simple and easy for on-line implementation. The different simulation results show the high performance and robustness of the controller in the presence of parameter variations and load disturbances. The speed control gives a fast dynamic response with no overshoot and zero steady state error. The decoupling between the flux and the torque is maintained with regard to parameter variations and external load disturbance. In the steady state, torque chattering is decreased when compared with the conventional control SMC.
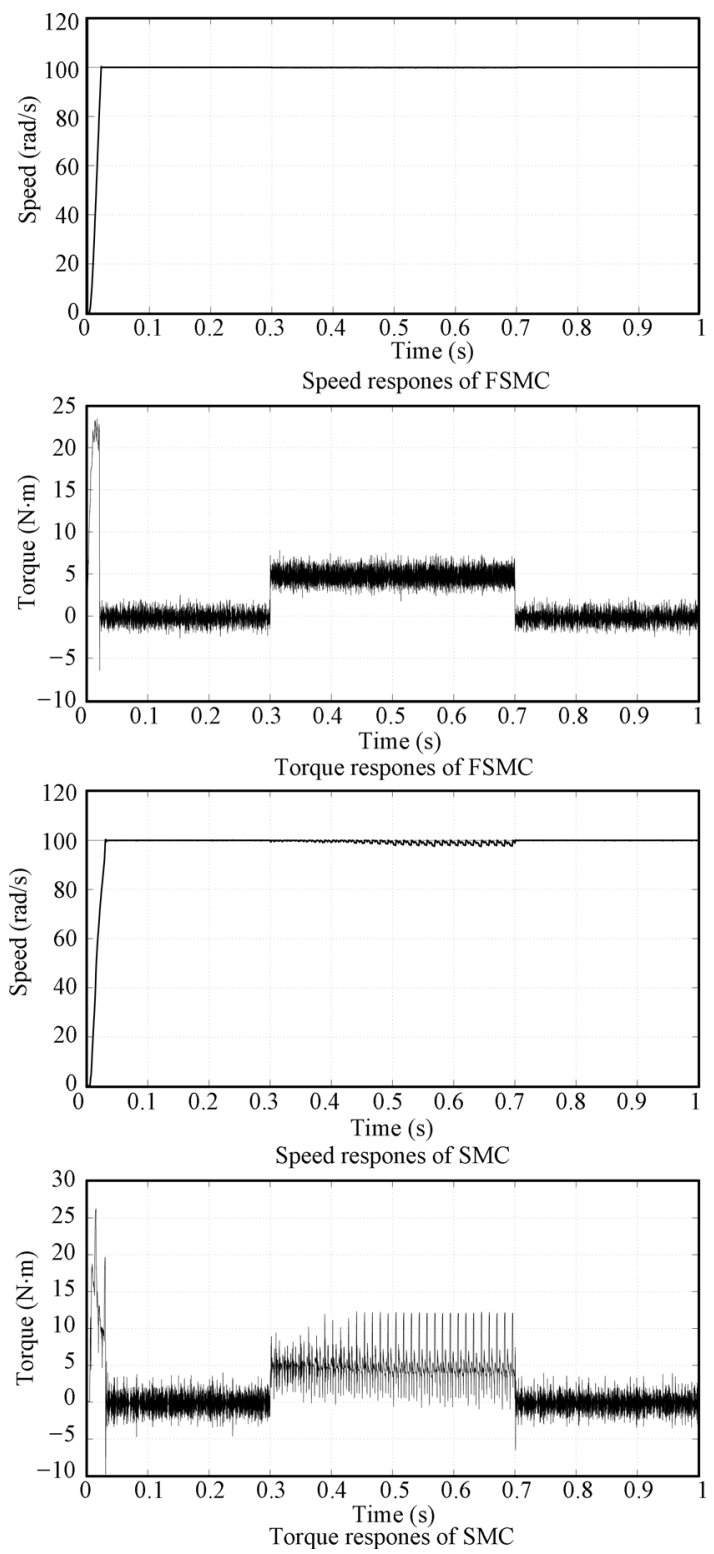

Fig. 7 Simulation results under stator and rotor resistance variations

\section{References}

[1] K. B. Mohanty. Development of fuzzy sliding mode controller for decoupled induction motor drive. Journal of Systems Science \& Engineering, Paritantra, vol. 8, no. 1, pp. 33-39, 2003.

[2] A. Benchaib, A. Rachid, E. Audrezet. Sliding mode inputoutput linearization and field orientation for real-time control of induction motors. IEEE Transactions on Power Electronics, vol. 14, no. 1, pp. 3-13, 1999.

[3] L. Barazane, A. Khwaldeh, S. M. M. Krishan, P. Sicard. Using an adaptive fuzzy-logic system to optimize the performances and the reduction of chattering phenomenon in the control of induction motor. Serbian Journal of Electrical Engineering, vol. 6, no. 2, pp. 267-284, 2009.

[4] A. Ltifi, M. Ghariani, R. Neji. Sliding mode control of the nonlinear systems. In Proceedings of the IEEE 11th Inter- 
national Workshop on Symbolic and Numerical Methods, Modeling and Applications to Circuit Design (SM2ACD), IEEE, Gammath, Tunisia, pp. 1-6, 2010.

[5] R. J. Wai, K. H. Su, C. Y. Tu. Implementation of adaptive enhanced fuzzy sliding-mode control for indirect fieldoriented induction motor drive. In Proceedings of the 12th IEEE International Conference on Fuzzy Systems, IEEE, St Louis, MO, USA, vol. 2, pp. 1440-1445, 2003.

[6] M. Ben Ghalia, A. T. Alouani. Knowledge-based robust control of complex systems. In Proceedings of IEEE International Conference on Systems, Man and Cybernetics, Intelligent Systems for the 21st Century, IEEE, Vancouver, BC, Canada, vol. 2, pp. 977-982, 1995.

[7] A. Hussain. Contribution a la Commande Adaptative Robuste par Modes Glissants, Ph. D. dissertation, Universite de Reims Champagne Ardenne, France, 2009. (in French)

[8] M. Xiao. Modeling and adaptive sliding mode control of the catastrophic course of a high-speed underwater vehicle. International Journal of Automation and Computing, vol. 10 no. 3, pp. 210-216, 2013.

[9] M. T. Cao. Commande Numérique de Machines Asynchrones par Logique Floue, Ph. D. dissertation, Universite Laval, Canada, 1997. (in French)

[10] A. G. Aissaoui, H. Abid, M. Abid. Robust fuzzy sliding mode controller design for motors drives. Acta Electrotechnica et Informatica, vol. 9, no. 2, pp. 64-71, 2009.

[11] C. M. Lin, C. F. Hsu. Adaptive fuzzy sliding-mode control for induction servomotor systems. IEEE Transactions on Energy Conversion, vol. 19, no. 2, pp. 362-368, 2004.

[12] H. F. Ho, K. W. E. Cheng. Position control of induction motor using indirect adaptive fuzzy sliding mode control. In Proceedings of the IEEE 3rd International Conference on Power Electronics Systems and Applications, IEEE, Hong Kong, China, pp. 1-5, 2009.

[13] P. Vidal. Commande Non-linéaire d'une Machine Asynchrone Double Alimentation, Ph. D. dissertation, National Polytechnic Institute of Toulouse, France, 2004. (in French)

[14] N. Abdelfatah, H. Abdeldjebar, I. K. Bousserhane, S. Hadjeri, P. Sicard. Two wheel speed robust sliding mode control for electric vehicle drive. Serbian Journal of Electrical Engineering, vol. 5, no. 2, pp. 199-216, 2008.

[15] E. Kemalettin, Y. Yildiray, S. Asif. Sliding Modes in Fuzzy and Neural Network Systems. The Institution of Engineering and Technology, London, United Kingdom: Control Engineering Series no. 66, pp. 245-262, 2004.

[16] W. Perruquetti, J. P. Barbot. Sliding Mode Control in Engineering, New York: Marcel Dekker, Inc., 2002.

[17] M. S. Agamy. Sliding mode control of induction motors with minimized control effort: A comparative study. In Proceedings of IEEE Canadian Conference on Electrical and Computer Engineering, IEEE, Saskatoon, Sask, Canada, pp. 2237-2240, 2005.
[18] J. H. Zhao, M. Y. Wang, Y. Li, Y. J. Zhou, S. X. Liu. The study on the constant switching frequency direct torque controlled induction motor drive with a fuzzy sliding mode speed controller. In Proceedings of IEEE International Conference on Electrical Machines and Systems, IEEE, Wuhan, China, pp. 1543-1548, 2008

[19] M. Allouche, M. Chaabane, M. Souissi, D. Mehdi, F. Tadeo. State feedback tracking control for indirect field-oriented induction motor using fuzzy approach. International Journal of Automation and Computing, vol.10, no. 2, pp.99-110, 2013.

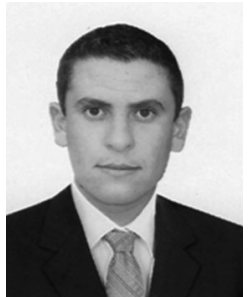

Ismail Bendaas graduated from Batna University, Algeria in 2001. He received his M.Eng. and M. Sc. degrees in electrical engineering at Batna University, Algeria in 2007 and 2011, respectively. Since 2011, he has been a Ph. D. candidate in Department of Electrical Engineering at University of Batna, Algeria.

His research interests include control and automation, especially the control of electrical machines by using hybrid and intelligent control.

E-mail: s_bendaas@hotmail.fr (Corresponding author)

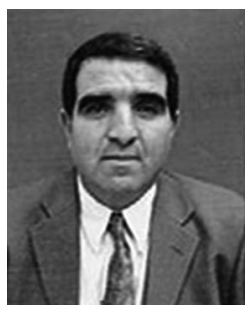

Farid Naceri graduated from Batna University, Algeria in 1987. He received his M. Sc. degree in 1992 and his Ph. D. degree from Batna University, Algeria in 2000, respectively. He is currently a professor at the Laboratory: Systems of Electrical Traction, LSTE.

His research interests include control and automation, especially the control of electrical machines using intelligent control.

E-mail: nacerifarid@yahoo.fr

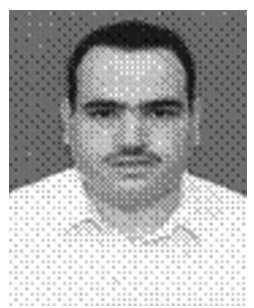

torque control.
Sebti Belkacem received his B. Sc. and $\mathrm{M}$. Sc. degrees in electrical engineering from the University of Batna, Algeria, and his $\mathrm{Ph}$. D. degree in 2011. He is an assistant professor at the Department of Electrical Engineering, University of Batna. He is a member in the Electrical Engineering Laboratory (LEB).

His research interests include adaptive control, nonlinear control, and direct

E-mail: belkacem_sebti@yahoo.fr 